\title{
Research on Organizational Capabilities Enhancement in Technological Innovation of Internet of Things*
}

\author{
Yue Cheng \\ College of Public Management \\ Guangxi University \\ Nanning, Guangxi, China 530004
}

\begin{abstract}
IoT (Internet of things) is an important part of new generation information technology. Facing the huge market, the enterprises shall respond to the national IoT development strategy demands, in order to develop further and enhance their competitiveness. Organizational capabilities theory in IoT technology innovation of the enterprises will be studied based on theory of enterprise resource, core competence theory, dynamic capabilities theory, knowledge based theory and risk assessment, providing theoretical support to the IoT technology innovation development as a response to the national IoT development strategy demands, to better service the social economy development.
\end{abstract}

Keywords-internet of things; organizational capabilities; technological innovation; risk management

\section{INTRODUCTION}

Internet of Things (IoT) is an important part of new generation information technology [1, 2]. In November 2005, the International Telecommunication Union (ITU) issued the ITU Internet Report 2005: Internet of Things, thus the concept of IoT was officially proposed. The purpose of IoT is to enable remote sensing and control of all things, and to connect to the existing network, forming a more intelligent production and living system [3]. On March 5, 2010, Premier Wen Jiabao proposed to vigorously cultivate strategic emerging industry, to speed up the research and application of IoT, and increase the investment in strategic emerging industry and policy support in the part of "accelerate transformation of economic development mode, adjust and optimize economic structure" of the Government Work Report.

Technology innovation is the fundamental source for enterprise to achieve scientific and technological progress, obtain the competitive advantage and promote economic growth, and the important basis for the survival and development of enterprises [4]. Enterprises gain the competitive edge relying on technological innovation, but technical innovation is a process full of risk and uncertainty, which may not only result in tangible economic losses of

*Project funding: Guangxi natural science funding project "Research on strategic emerging industries coordinated with innovative network evolution and operation mode-taking Guangxi biological medicine industry as an example" (2014GXNSFBA118026), humanities and social science research project approved by Guangxi higher education institutions "Formation and role of ethnic minority members in Entrepreneurial Team-empirical study from Guangxi” (SK13LX021). enterprises, but also lead to such intangible losses as time loss, opportunity loss and psychological damage [5]. The research on relevant theory of Organizational Capabilities will enhance enterprise innovation efficiency and quality effectively against enterprises' technological innovation in the development of IoT. And through the theoretical research on risk assessment on IoT technological innovation, the influence on enterprise innovation by environmental uncertainty will be reduced, which is conducive to enhance enterprise's response speed against environmental changes in terms of IoT technological innovation.

Enterprise competence promotion mechanism in IoT technological innovation will be studied in this paper. And provide theoretical guidance of technological innovation development for enterprise in the rapid development of IoT, enhance the efficiency of technological innovation development, reduce the risk and save the cost in view of the basic theory problems of organizational capabilities in the process of IoT technological innovation, thus to solve the current condition of Chinese enterprises' lack of targeted organizational capability management theory in the process of IoT technological innovation.

\section{DOMESTIC AND FOREIGN RESEARCH STATUS AND DEVELOPMENT TRENDS}

\section{A. Development Status of Internet of Things}

IoT has become a development strategy of many countries. On April 8, 2005, the "International Expert Team of Ubiquitous Network Society" was established specially by the International Telecommunication Union on World Summit on the Information Society (WSIS) held in Geneva, providing a permanent consulting institution to discuss IoT internationally. According to the report of this team, many countries have started their development strategy of "Internet of Things" since $2005[6,7]$. The Iot is listed as one of the six key technologies in the Key Technologies Potentially Affect American Interests in 2025 as published by the National Intelligence Council (NIC). In April 2005, the Executive European Commission formally announced a policy framework of "i2010" for the EU information communication, putting forward the integration of different communication networks, content services and 
terminal equipment, to provide a consistent management structure to adapt to the globalized digital economy, and develop the technology which is more market-oriented, flexible and future-oriented [8-10]. Japan UID system established under T-Engine has been used well in this country, and will be promoted vigorously to other countries, especially Asian countries. In October 2009, the Korea Communications Commission approved the Basic Planning of Infrastructure Construction for Internet of Things, regarded IoT market as a new growth engine, and determined such 4 areas as IoT Infrastructure Construction, IoT Service Development, IoT Technology R\&D and IoT Diffusion Environment Creation and 12 detailed topics [6]. The key technology of IoT has also been used widely in China. The two dimensional coding technology has been widely used in animal source tracing, the automatic production line of automobile industry, public security, diplomatic, military and other areas [11]. But at present, China's IoT technology is still in the starting period of scattered application, and there is great distance to large-scale industrialization promotion, with the problems mainly reflected in the following aspects: (1) great difficulty in industry convergence; (2) lack of unified technical standards; (3) lack of sustainable business model; (4) policy environment need to be perfected [6].

Innovation and breakthrough of IoT is the basic guarantee of industrial development against the above problems. In the process of IoT technology innovation, it is essential for enterprises to conduct organizational capability management, including technological innovation management, as well as risk assessment on technology innovation and policy support $[12,13]$.

\section{B. Current Situation of Theoretical Research on Organizational Capability}

Organizational Capabilities theory considers enterprise as an aggregation of capability. Since $1960 \mathrm{~s}$, the researchers of this theory has pointed out further that the key hidden behind the organizational capabilities and determines its competitive advantage is the knowledge mastered by the enterprise, particularly the tacit knowledge that is difficult to be imitated by competitors as well as the cognitive learning closely related to the knowledge, namely the use of knowledge or skill [1419]. Trygg, Verona and Eisenhardt $\mathrm{K}$ have pointed out that the process of product development is a set of capabilities, of which the success lies in the effective use of internal and external resources $[14,20]$. Organizational Capabilities (especially the dynamic ability) are very important to the success of product research and development [21, 22]. Brown S L [23], Krishnan V, Sivadas E, etc. pointed out that the product development process is dependent on four kinds of organizational capabilities based on the perspective of resource reconfiguration: coordination ability, absorption capacity, integration ability and dynamic ability [14]. Among them, the importance of absorptive capacity for the product development is widely recognized by the scholars. Jianfeng $\mathrm{Wu}$ pointed out that the success of product research and development is related to three types of organizational capabilities: accumulation ability, search ability and integration ability. Ulrich $\mathrm{K} \mathrm{T}$ and others described four capabilities to be cultivated in this process respectively: technical ability, marketing ability, internal integration and external integration ability. Henderson holds the opinion that, Organizational Capabilities system includes two aspects: components ability and architecture ability [24].

With the increasing uncertainty and complexity of enterprise management environment, the theory researchers began rethink and expand the internal logic structure and its evolution law of the organizational capability, and pay more attention to organization knowledge structure, the evolution of organizational knowledge itself, and the dynamic analysis of its matching to environmental changes which play a key role on enterprise strategy [19]. These relevant studies can be summarized as dynamic capabilities, absorption ability and transformation ability, of which their common characteristic is to describe the source and formation process of unique organizational ability using the dynamics and heterogeneity of organizational knowledge structure. And at the theoretical level, taking the dynamic analysis on economy by evolution economists of Nelson and Winter and epistemologist of Polanyi, the contribution of Nonaka, Tecce, Grant and Gerard is enriched greatly [19].

Chu Tianjiao [25], one of the domestic scholars, points out from the perspective of enterprise resource view that, product research and development ability of an enterprise is a collection of capabilities, including resource acquisition ability, organization integration ability, achievement transformation ability and environmental supporting capacity [14]. After a comprehensive survey on existing research results, Xing Xiaoqiang and Gong Yunhuan [26] point out that enterprise product development process is a set of knowledge, enable the research and development ability to be increased and spread through acquisition of the internal and external knowledge. And network capacity reflects the acquisition ability of external knowledge, while technical capacity embodies the integration capability of internal knowledge. Therefore, from the perspective of ability's knowledge property and its application characteristics, the success of enterprise product research and development mainly need two kinds of organizational capabilities: network capability and technical capability, to mainly inspect the difference of different organizational capabilities for external knowledge absorption and internal knowledge integration, and the impact on the research and development of product by their interaction [14]. Wang Yi, Chen Jin, Xu Qingrui and others divide the organizational capabilities into three levels from the perspective of ability carrier and comprehensive degree levels on the basis of Henderson frame concept: ability at technology integration layer, ability at business layer and capability at operating environment layer [27].

\section{ANALYSIS ON CHINA'S IOT TECHNOLOGY INNOVATION AND COMPETITIVENESS}

The basic theory research on Organizational Capabilities is carried out against the IoT development, and the research on IoT development trend and demands is the basic premise. The globalization of various industries makes the full interpretation of international development trend of IoT industry, its development situation in China, as well as the location in 
global industrial chain and development needs the primary problem to be solved.

Internationally, the United States has gradually created an IoT industry strong strength relying on its technical advantages in such areas as chip, software, Internet and high-end application integration. Currently, with respect to the IoT application, the European M2M market is quite mature with balanced development, and various countries in European Union have formed certain scale of IoT application in the field of electric power, transportation and logistics. Japan has developed such IoT businesses as disaster protection and mobile payment with emphasis against its domestic characteristics. In China, the emerging strategic industries including IoT were involved in the Government Work Report at the beginning of 2010. The first China Internet of Things Conference was held in Beijing on June 29, 2010, and the latest consensus about IoT concept was concluded at this conference, namely: the Internet of Things is a network of instrumentation, interconnection and intelligent, and its technology development goals are: comprehensive perception, reliable transmission and intelligent processing.

In general, various countries' IoT development is still dependent on the technological path of the United States to a certain degree. On the one hand, this is because the IoT technology cannot be developed without the Internet technology standard as dominated by America in the past and at present; on the other hand, it is the long term basic research, accumulation and strong technical reserves in the field of IT in American, and at the same time, America is good at promoting the formation of a new generation of industrial technology dominant design standard using the method the concept innovation. Therefore, the settlement of path dependence will create a huge market in IoT technology innovation for Chinese enterprises. At the same time, the competitiveness analysis on Chinese enterprises in IoT industry is also very important. The improvement of Chinese IoT industry competitiveness shall be conducted mainly starting from the several aspects as shown in "Fig. 1".

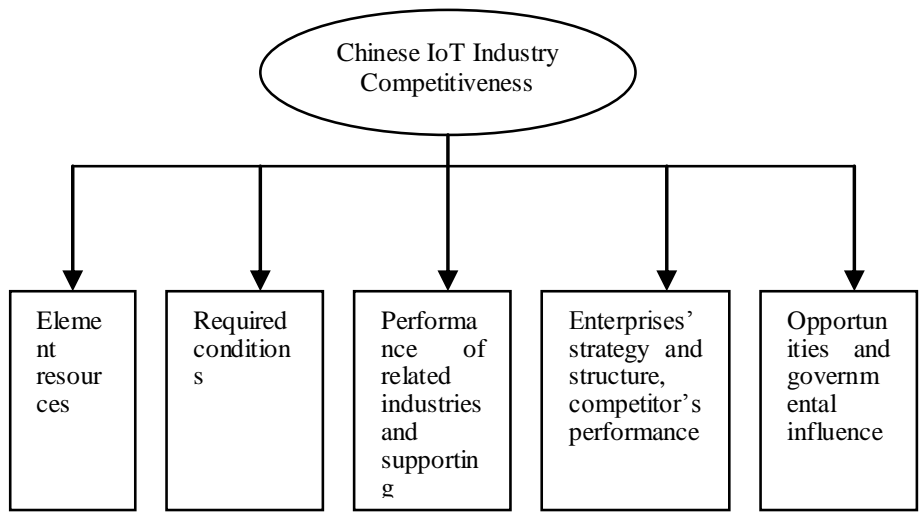

Fig. 1. Analysis on chinese iot industry competitiveness

\section{ORGANIZATIONAL CAPABILITY ENHANCEMENT MECHANISM IN IOT TECHNOLOGY INNOVATION}

Through the above analysis on China's IoT industry competitiveness, it can be seen that the development of this industry needs sufficient support of internal and external conditions. Some of these conditions have developed relatively mature, while others still need to be further strengthened. In the process of overcoming these disadvantages, the ability improvement and development of IoT enterprises themselves is the key. Generally speaking, the Organizational Capability enhancement in the process of IoT technology innovation can be made from the following aspects.

\section{A. Key Enterprise Resources Support}

Some key resources and capabilities are required in the IoT technology Innovation of enterprises. First of all, the enterprise's sustainable competitive advantage in IoT technology development is determined by the enterprise's source "potential obstacles", and its own advantage resources will be converted into cost advantage. The resources which are valuable, scarce, and which cannot be imitated and replaced completely in IoT technology innovation are the necessary conditions for enterprise to gain competitive advantages. The competition restrictions afterwards by the enterprise, incomplete liquidity of enterprise resources and competition prevention by the enterprise are the sufficient conditions for the enterprise to gain competitive advantages. In addition, all the financial and material resources, human and organizational resources used by the enterprise to develop, produce and distribute products and serve the consumers in the IoT technology innovation will also be the key resource support for enterprise to carry on IoT technology innovation.

\section{B. Cultivation of Enterprise's Core Capability}

Essentially, the enterprise is a collection of capabilities. And the decision elements of an enterprise's ability in IoT technology innovation include long-term accumulation and learning, the initial inputs, additional inputs, enterprise experiences and so on. In the process of IoT innovation, the core capabilities include the following two aspects: first is the "team" of people; the second is the enterprise shall own the resources or assets. The reserve status of core ability determines the enterprise's business scope. The core capability owned by enterprise is the source for the enterprise's sustainable competitive advantage in IoT development. In the process of IoT technology innovation, after the special ability which may bring the competitive advantages has formed in an enterprise, it can be applied to other business units, to achieve competitive advantage.

\section{Enhancement of Enterprise Dynamic Ability}

The dynamic capability of enterprise in IoT technology innovation refers to ability of integration, establishment and relocation of internal and external resources and capacity. Dynamic capability is a knowledge characteristic which generates diversified business, rendering the enterprise first move advantage in the process of IoT technology innovation, to adapt to the dynamic environment. Dynamic capability enables the enterprise to maintain or change its competitive advantage base. The formation of dynamic capability of an enterprise in IoT technology innovation requires the coordination, integration and the innovation of knowledge, which mainly reflected in the operating style, rules, procedures, 
practices, strategies and technologies to be built and operated by the enterprise. We need to consider enterprise as a knowledge system, and regard it as an integrated effective mechanism for acquisition, application and innovation of knowledge required in the process of production and providing services in IoT technology innovation. The knowledge difference formed and accumulated in the enterprise's IoT technology innovation will cause enterprise's heterogeneity.

\section{Carry out Necessary Risk Assessment}

The essential starting point of an enterprise to develop IoT technology is to improve enterprise benefits, and at the same time it assumes the risk of technology development. Reduce or avoid risk will effectively improve the efficiency of the enterprise's research and development. As for the enterprises who conduct IoT technology innovation, risk management is to deal with the risks in a planned way by selecting effective means through risk identification, prediction and measurement, to reduce costs as much as possible, thus to acquire the economic guarantee for enterprise's safety production. This will require enterprises to identity possible risks and predict the negative impact on resources and production operation in the process of production and operation, to gain a sustainable production. As a result, risk identification, prediction and treatment are main steps of enterprise's risk management, as shown in "Fig. 2".

We can adopt the following methods to conduct the study in specific evaluation process: (1) baseline risk assessment: to conduct risk identification of the system based on various segments of the process (based on the type of work and task) and areas, which suitable for regular assessment; (2) risk assessment based on problems is to conduct detailed evaluation and research on the major risks identified in risk overview, and to provide clear advice to management. The problems-based risk assessment is a complement and reinforcement of risk overview; (3) sustainable risk assessment is the dynamic risk assessment conducted by individual uninterruptedly without considering location, and it is the continuous improvement of risk assessment.

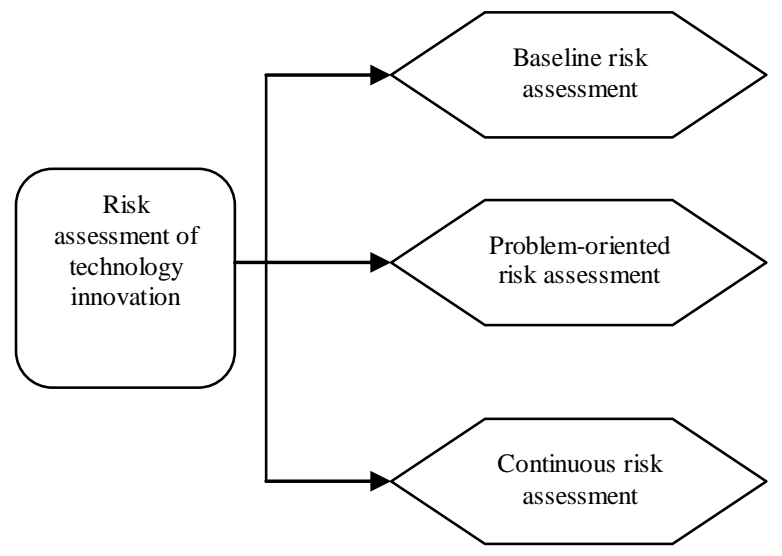

Fig. 2. Risk assessment of IoT technology innovation

\section{FUTURE POLICY RECOMMENDATIONS}

In order to further accelerate the technological innovation of Chinese IoT industry and enhance enterprise innovation ability, in the future, we need to perfect the policy environment of IoT industry and promote healthy development of the industrial chain. Through the opening industrial investment policy and preferential tax policies, lead various state-owned, private and international capital to be invested in the IoT industry, break the trade barriers, permit cross-industry investment, construct infrastructure and public facilities, and actively promote critical applications. Especially at the start-up stage, we shall encourage the open of industry chain. And create an open industry environment on the premise that information safety is guaranteed, through appropriate easing access policy, price policy and other policies, to lay a solid foundation for the development of Chinese IoT industry. In addition, the competent authority of IoT industry shall start to cultivate this industry from such five aspects of fostering the IoT application, encouraging enterprises to set up innovation mechanism, establishing the IoT standard, creating the industrial chain of IoT to transform the inventions into productive forces and formulating guideline for IoT development.

\section{REFERENCES}

[1] Yu Cheng. Internet Technology and the Challenges Encountered in China [J]. Software, 2011, 32(5): 109-111.

[2] Peng-Fei F, Guang-Zhao Z. Analysis of the business model innovation of the technology of internet of things in postal logistics[Z]. 2011532536.

[3] Xu Diwei, Cai Jianxin. Internet of Things and Analysis on its Application [J]. Computer Engineering and Applications, 2011(15): 1-2.

[4] Yuan Haijun. Application of Project Management in Enterprise Technological Innovation Management [J]. Development \& Innovation of Machinery \& Electrical Products, 2011(6): 19-21.

[5] Guan Xuefang. Strengthen Technological Innovation Management and Achieve Leap Forward Development [J]. Metallurgical Collections, 2004(1): 36-41.

[6] Li Xiangwen. Internet of Things Development Strategy of Europe, America, Japan, Korea and China-Global Development Action of Internet of Things [J]. Radio Frequency World, 2010(3): 49-53.

[7] Mei Fangquan. Smart Planet and Sensation China-Analysis on Internet of Things Development [J]. Agriculture Network Information, 2009(12): 5-7.

[8] Shi Yu, Sun Yunchuan, Chen Danyang. Series Three of European Internet of Things Research Strategy Roadmap-Key Technologies supporting the Development of Internet of Things [J].China Auto-ID, 2010(5): 50-56.

[9] Shi Yu, Sun Yunchuan, Chen Danyang. Series Four of European Internet of Things Research Strategy Roadmap - key Research Domains of Future Internet of Things Identification Technology and Standard [J]. China Auto-ID, 2010(6): 50-52.

[10] Gao Linpeng. Problems of EPCglobal Network Framework in Economy, Safety, Privacy and Management concerned in the European Internet of Things Conference 2008 [J]. Information Technology \& Standardization, 2008(11): 10 .

[11] Shao Wei, Li Li. Sensation China-Study on China's Internet of Things Development Path $[\mathrm{J}]$. China Science and Technology Information, 2009(24): 330-331

[12] Wang Lixin, Gao Changchun, Ren Rongming. Study on the Evaluation System and Evaluation Methods of Enterprise Innovation Capability [J]. 
Journal of East China Institute of Technology (Natural Science Edition), 2006(3): 34-37.

[13] Yu Weiping, Cui Miao. Optimization Analysis on Value Chain based on Organizational Capabilities under the Context of Economic Globalization [J]. China Industrial Economy, 2003(5): 42-47.

[14] Wang Lingling, Fang Runsheng. Study on the Inter Relationship of Different Types of Enterprises' Ability in the Product Research and Development Process [J]. Group Technology \& Production Modernization, 2009(4): 19-25.

[15] Xu Rui, Li Yuan. Enterprise Competitive Advantage Cultivation based on Dynamic Ability [J]. Journal of Intelligence, 2006(3): 89-91.

[16] Wang Yi, Wu Guisheng. Study on Enterprise Dynamic Core Ability based on Complex Theory [J]. Journal of Management Sciences in China, 2007(1): 18-28.

[17] Chooprayoon V, Chun C F. Thailand open ICT ecosystems: A scenario analysis of electronic commerce infrastructure investment for small and medium enterprises[Z]. 2008254-259.

[18] Maier A M, Moultrie J, Clarkson P J. Assessing Organizational Capabilities: Reviewing and Guiding the Development of Maturity Grids[J]. Engineering Management, IEEE Transactions on, 2012, 59(1): 138-159.

[19] Zhang Xi. Latest Development Comment on Knowledge-based Organizational Capabilities Theory [J]. Modern Management Science, 2005(12): 46-48.

[20] De Luca L M, Verona G, Vicari S. Market orientation and R and D effectiveness in high-technology firms: An empirical investigation in the biotechnology industry[J]. Journal of Product Innovation Management, 2010, 27(3): 299-320.

[21] Gao Ruxi, Lu Guofeng. Marketization Degree, Organizational Capabilities and the Impact on Chinese Industrial Organization [J]. Exploration and Free Views: 24-26.

[22] Zhao Jian. Comparative Advantage and Industrial Policy of Chinese Independent Development-Analysis based on Organizational Capabilities Theory [J]. China Industrial Economics, 2008(8): 76-86.

[23] Brown S L, De Jager D, Wood R, et al. A pharmacy stock control management system to effectively monitor and manage patients on ART[Z]. London, United kingdom: 200627-35.

[24] Wang Xiqiu, Xi Youmin. Research on Innovation of China Organizational Capabilities Structure [J]. Value Engineering, 2002(5): 2-6.

[25] Chu Tianjiao, Du Debin, Jiang Tao. Survey on R\&D Capability of 143 State-owned Industrial Enterprises[J]. Forum on Science and Technology in China, 2008(3): 63-66.

[26] Xing Xiaoqiang, Gong Yunhuan. Research on the Relationship between Enterprise Network Ability and Technological Ability under the perspective of Innovation [J]. Science of Science and Management of S.\&.T., 2007(12): 182-186.

[27] Wang Yi, Chen Jin, Xu Qingrui and others. Research on Concept Framework of Enterprise Core 